\title{
Protective ileostomy: complications and mortality associated with its closure
}

\author{
Mónica Mengual-Ballester ${ }^{1}$, José Andrés García-Marín², Enrique Pellicer-Franco ${ }^{1}$, \\ María Pilar Guillén-Paredes², María Luisa García-Garcíaª ${ }^{2}$, María José Cases-Baldó \\ and José Luis Aguayo-Albasini ${ }^{3}$
}

${ }^{1}$ Department of General Surgery and Digestive Diseases. School of Medicine. Universidad de Murcia. Spain. ${ }^{2}$ Department of General Surgery and Digestive Diseases. Hospital General Universitario Morales Meseguer. Murcia, Spain. ${ }^{3}$ Universidad de Murcia. Spain

\begin{abstract}
Introduction: diverting loop ileostomies are widely used in colorectal surgery to protect low rectal anastomoses. However, they may have various complications, among which are those associated with the subsequent stoma closure. The present study analyses our experience in a series of patients undergoing closure of loop ileostomies.

Method: retrospective study of all the patients undergoing ileostomy closure at our hospital between 2006-2010. There were 89 patients: 56 males $(63 \%)$ and 33 females $(37 \%)$ with a mean age of 55 (38-71) years. The most common indication for ileostomy was protection of a low rectal anastomosis, 81 patients (91\%). The waiting time until stoma closure, type and frequency of the complications, length of hospital stay and mortality rate are analysed.

Results: waiting time before surgery was 8 (1-25) months. Fortyone patients (45,9\%) developed some type of complication, three were reoperated (3.37\%) and one patient died (1.12\%). The most important complications were intestinal obstruction (32.6\%), diarrhoea (6\%), surgical wound infection (6\%), enterocutaneous fistula $(4.5 \%)$, rectorrhagia (3.4\%) and anastomotic leak (1.12\%). The mean length of patient stay was 7.54 (2-23) days.

Conclusions: protective ostomies in low rectal anastomoses have proved to be the only preventive measure for reducing the morbidity and mortality rates for anastomotic leakage. However, creation means subsequent closure, which must not be considered a minor procedure but an operation with possibly significant complications, including death, as has been shown in publications on the subject and in our own series.
\end{abstract}

Key words: Loop Ileostomy. Clousure of ileostomies. Complications of ileostomies.
Mengual-Ballester M, García-Marín JA, Pellicer-Franco E, GuillénParedes MP, García-García ML, Cases-Baldó MJ, Aguayo-Albasini JL. Protective ileostomy: complications and mortality associated with its closure. Rev Esp Enferm Dig 2012;104:350-354.

\section{INTRODUCTION}

Diverting ileostomies are widely used in colorectal surgery to protect low rectal anastomoses, especially in techniques such as low anterior resection and restorative protocolectomy. Although their presence does not reduce the total incidence of anastomotic leakage, it does reduce related morbidity and therefore the need for reoperation as well as the mortality rate of these patients (1).

However, ileostomies are not without their drawbacks as they represent a reduction in the patients' quality of life (2) and may present various complications, such as hydroelectrolytic alterations, bowel obstruction, infection of soft parts, incisional hernias, etc. But it is stoma closure that carries the highest rates of morbidity and mortality (3).

We believe that the closure of diverting ileostomies should not be considered a complication-free minor surgical procedure; for this same reason we analyse our experience in a series of patients undergoing closure of diverting loop ileostomies between 2006-2010.

\section{PATIENTS AND METHODS}

Retrospective study including all the patients undergoing ileostomy closure at the José María Morales Meseguer Hospital in Murcia, Spain between January $1^{\text {st }}, 2006$ and December $31^{\text {st }} 2010$.

\section{Data collection}

Data were collected retrospectively and entered into a database created for this purpose. The study population was 
selected from a historical archive of patients receiving programmed surgery in the General Surgery department; this archive allows identification of the process for which the patient undergoes surgery and is ordered chronologically.

\section{Patient characteristics}

The series is made up of 89 patients: 56 males (63\%) and 33 females (37\%), with a mean age of 55 (38-71) years.

The most common diagnosis for previous surgery was rectal neoplasia in 70 patients $(78.65 \%)$, followed by pancolitis in 8 cases (9\%), familial adenomatous polyposis in $5(78.65 \%), 2$ dehiscences of previous anastomoses $(2.25 \%)$, perianal Crohn's disease in 2 patients $(2.25 \%)$, recto-vaginal fistula in $1(1.12 \%)$ and sigmoid diverticulitis in 1 patient $(1.12 \%)$.

All the patients are carrying of loop ileostomia; the ostomy was performed in most patients as a programmed operation; only 7 cases received emergency surgery: 3 patients with anastomotic dehiscence ( 2 ileocolic and 1 colorectal), one case of pancolitis in an ulcerative colitis with haemodynamic involvement and 2 colonic perforations secondary to obstructive neoplastic processes.

As for the anesthesic-surgical risk according to ASA'S classification (American Society of Anesthesiologists): 44 patients (49.4\%) were ASA III, 32 (36\%) ASA I and only $13(14.6 \%)$ ASA III.

The surgical technique performed together with the ileostomy was low or ultra-low anterior resection in 64 cases $(72 \%)$, restorative proctocolectomy with a "J" reservoir in 13 patients $(14.5 \%)$, subtotal colectomy in 7 cases (7.9\%), diverting ileostomy as a single technique in 3 patients $(3.4 \%)$ and finally a high anterior resection in 2 patients $(2.2 \%)$.

The most common indication for ileostomy was to protect a low anastomosis, in a total of 81 patients $(91 \%)$, including those with an ileal J-pouch reservoir. The rest consisted in protection of the anastomosis in the context of a peritonitis $(n=5)$ and in 3 patients with the intention of temporarily diverting transit.

Of all the patients undergoing ileostomy closure, 91\% had a preoperative imaging test to confirm the integrity and proper calibre of the anastomosis and to ensure the absence of any process that might contraindicate closure of the stoma. The most commonly chosen test was abdominal computed tomography with oral contrast and gastrograffin enema, performed in $64.2 \%$ of the cases, followed by colonoscopy in $32 \%$ and finally by opaque enema in $3.8 \%$ of the patients.

\section{Surgical technique}

All the patients were given antibiotic prophylaxis with ceftriaxone prior to surgery and rachideal anaesthesia. The approach was via a peristomal incision; the ileostomy was pulled out and the edges refreshed. The anastomosis was performed manually in 87 cases and mechanically with GIA 60 in 2 cases. Those done manually were end-to-end, with slowabsorption monofilament suture (Byosin ${ }^{\circledR}$ ), $73 \%$ with loose extramucous sutures and the remaining $27 \%$ with two interrupted sutures.

Later there was realized closing of the abdominal wall by planes by running suture of material monofilament of slow-absorption, and closing of cellular subcutaneous by interrupted suture of monofilament.

\section{Data analysis}

Quantitative variables are expressed as mean \pm standard deviation and the qualitative variables as percentages with their $95 \%$ confidence intervals. Comparison between the 2 groups was made with the Pearson Chi-squared test or Fisher exact test for qualitative variables. Statistical significance was considered for a $\mathrm{p}$-value of $<0.05$.

\section{RESULTS}

\section{Waiting time before surgery}

The mean waiting time between creation of the ileostomy and closure was 8 months (1-25). Here there are significant differences between patients who had adjuvant chemotherapy after construction of the ileostomy (37\%) and those who did not $(63 \%)$. The mean waiting time was 9.81 months in the former group but 6.91 months in the latter $(\mathrm{p}=0.003)$.

\section{Postoperative complications}

Forty-one (45.9\%) of the 89 patients developed some type of complication and even $14.6 \%$ developed several complications.

The most common was intestinal obstruction, that happened in 29 patients (32.6\%), which was resolved in all cases with conservative treatment; in second place was diarrhoea and surgical wound infection, which occurred in 5 patients $(6 \%)$ in both cases. In third place, enterocutaneous fistula, with a frequency of $4.5 \%$, any of which required surgery after being resolved with conservative treatment.

Other less common complications were rectorrhagia in 3 patients (3.4\%) and one anastomotic leak (1.12\%), which was treated with radiological drainage. Minor events included two cases of phlebitis (2.24\%), an infection of the urinary tract $(1.14 \%)$ and an episode of paroxysmal auricular fibrillation $(1.14 \%)$.

Three of the total patients $(3.37 \%)$ required reoperation, two as a result of dehiscence of the ileostomy suture. It was necessary in both cases to resect the anastomosis and create a new ileostomy, terminal in these cases. The third reoper- 
ation was performed in a patient who developed an ischemia of the anastomosis; this was the only death in our series, caused by septic shock secondary to peritonitis on day 7 after the second operation.

The relation between the classification of the anesthesicsurgical risk according to the ASA and the complications developed by the patients has been analyzed, not finding relation between both variables, so that the group that developed more complications was that of risk ASA II, 24 patients (54.5\% of this group), opposite to 12 patients $(37.5 \%)$ of ASA I and 5 patients of ASA III $(38.46 \%)$, with $p=0.289$.

Also the relation between the chemotherapy received by the patients before the closing of ileostomía and the development of complications has been studied, not finding relation between both variables; this way of 33 patients who received chemotherapy, 11 developed complications (33.3\%), opposite to 30 patients $(53.57 \%)$ who did not receive adjuvant treatment, with one $\mathrm{p}=0,064$.

\section{Mean length of stay}

The mean length of patient stay was 7.54 days (2-23). It increased significantly for those developing postoperative complications, compared to those who were complicationfree, such that the mean postoperative length of stay was 4.58 days for the latter group, rising to 11 days for those who had complications $(\mathrm{p}<0.005)$.

\section{DISCUSSION}

Complications in colorectal surgery have decreased in recent years due to the creation of specialised units (4); however, when they occur they associate high rates of morbidity and mortality, especially the feared anastomotic dehiscence. Protective ostomies in low anastomoses (after low anterior resection or restorative procrocolectomy) have proved to be the only preventive measure for reducing the morbidity and mortality with dehiscences of this type of anastomosis; although they do not prevent them they do reduce their impact and the number of reoperations $(5,6)$.

Despite existing beneficial evidence, there is no established indication for performing protective ostomies. Therefore, creating an ostomy or deciding on which type to do is left at the surgeon's criterion and based on factors such as type and locoregional conditions of the anastomosis, difficulties arising during surgery, associated patient morbidity, etc. Moreover, the surgeon must take into account on the one hand the potential benefit of the ileostomy in protecting the anastomosis, and on the other hand the drawbacks involved, such as the reduced life quality of ostomy patients (2) and the morbidity and mortality associated with the future closure of the ostomy.

One of the controversial points is the optimum time interval between the creation of the ileostomy and the time of closure. There are groups that incline towards an early stoma closure during hospital admission with a view to improving the patients' quality of life and preventing possible stomal complications, such as Alves et al. (7) and de Mengaux et al. (8), who perform early closure on postoperative days 8 and 10 with good results. However, most groups favour a late closure, between 8.5 weeks and six months after surgery; they encounter a higher morbidity rate both in closures done before 8.5 weeks (9), due to oedema of the ileostomy and still-firm intraabdominal adhesions, and in closures performed after the sixth month postoperatively $(9,10)$. Delayed closure of the ileostomy is often related to the adjuvant chemotherapy that many of these patients receive, as occurs in our series, in which the mean waiting time increases in the chemotherapy group, compared to those not receiving adjuvant treatment (6.91 vs. 9.81 months).

Although in the literature groups as of the Thalmeir et al. (2) show a higher morbidity rate with ileostomy closure in patients receiving adjuvant treatment, In our series we could not confirm this relationship, and have not demonstrated the relation between the preperative ASA and the complications either; probably these results are due to our series is not very large.

During this pre-closure waiting period an imaging test is usually performed to check the integrity of the anastomosis and diagnose the presence of fistulas or stenosis, although it is not clear if it is strictly necessary in all cases. On the one hand, the use of gastrograffin enemas in the immediate postoperative period is not recommended in patients with no clinical suspicion of dehiscence, as the increase in pressure on the anastomosis may lead to a disruption, or to a bacteraemia in the event of a subclinical local septic process; it should therefore not be done before the $6^{\text {th }}-8^{\text {th }}$ week postoperatively (11); moreover, false positive rates of $6.4 \%$ and false negative rates of $3.5 \%$ have been observed (12). Enema is only recommended therefore in those with a suspected anastomotic complication, as routine administration is highly questioned (11-13). The use of computed tomography with rectal contrast demonstrates the same drawbacks as gastrograffin enema, although it has the advantage of being able to evaluate possible local septic processes (14).

On the other hand, evaluation of the anastomosis using rigid or flexible sigmoidoscopy in the hands of experts has proved to be safe after the first 24 hours postoperatively (15). Exploration of a low anastomosis using rectal palpation allows identification of anastomotic defects without the need for enema; however, it does not allow good assessment of the presence of fistulas (12). On the basis of this evidence, Matthew (13) recommends conducting a digital and endoscopic examination of the anastomosis between the $4^{\text {th }}$ and $6^{\text {th }}$ week postoperatively and only if an anastomotic complication is suspected carrying out a radiological test to confirm it.

Another of the points for discussion is the type of anastomosis to perform in the ileostomy closure. There are groups that favour a lower rate of complications associated with a mechanical rather than a manual anastomosis, espe- 
cially bowel obstruction $(16,17)$. However, other studies, such as the meta-analysis conducted by Leung, find no significant differences between the two modes of reconstruction (18). Our group performed manual anastomosis in $97.7 \%$ of the patients, which means we cannot offer data on which type of anastomosis is better.

The rates of closure-related mortality are very varied in the studies published, ranging from $0.06 \%$ (3) to $6.4 \%$ (19): the mortality rate in our series was $1.12 \%$, due to the death of a patient presenting with an anastomotic ischaemia.

As for morbidity, we had a $45.9 \%$ rate of complications, the most common being intestinal obstruction. Our series coincides with the most common closure-related complications published in the literature: intestinal obstruction, surgical wound infection, intraabdominal infections, enterocutaneous fistula and anastomotic dehiscence $(3,20)$. We had a high complication rate, compared to other series reporting morbidities of 11.4 (3) or 33.8\% (19), probably due to a more exhaustive data collection. Most of our complications were solved conservatively and the reoperation rate was just $3.37 \%$, compared to rates of $7.4 \%$ (1) published in the literature.

In conclusion, the creation of diverting loop ileostomies implies paying the price associated with the complications of the future surgical closure. The decision, therefore, to create and subsequently close an ileostomy should not be considered a minor surgical process and the surgeon should take into account which patients will really benefit from it (cases of low anastomoses, presence of adverse conditions for healing of the anastomosis, etc.) and compensate for the risks involved with closure.

\section{REFERENCES}

1. Courtier R, Parés D, Silva CA, Gil MJ, Pascual M, Alonso S, et al. Clinical results of loop ileostomy closures in rectal cancer surgical patients. Effect of chemotherapy in the waiting period. Cir Esp 2010; 88(5):308-13

2. Thalheimer A, Bueter M, Kortuem M, Thiede A, Meyer D. Morbidity of temporary loop ileostomy in patients with colorectal cancer. Dis Colon Rectum 2006;49(7):1011-7.

3. Wong KS, Remzi FH, Gorgun E, Arrigain S, Church JM, Preen M, et al. Loop ileostomy closure after restorative proctocolectomy: outcome in 1,504 patients. Dis Colon Rectum 2005;48(2):243-50.
4. Smedh K, Olsson L, Johansson H, Aberg C, Andersson M. Reduction of postoperative morbidity and mortality in patients with rectal cancer following the introduction of a colorectal unit. Br J Surg 2001; 88(2):273-7.

5. Peeters KC, Tollenaar RA, Marijnen CA, Klein Kranenbarg E, Steup WH, Wiggers T, et al. Dutch Colorectal Cancer Group. Risk factors for anastomotic failure after total mesorectal excision of rectal cancer. Br J Surg 2005;92(2):211-6.

6. Gastinger I, Marusch F, Steinert R, Wolff S, Koeckerling F, Lippert $\mathrm{H}$; Working Group 'Colon/Rectum Carcinoma'. Protective defunctioning stoma in low anterior resection for rectal carcinoma. Br J Surg 2005;92(9):1137-42.

7. Alves A, Panis Y, Lelong B, Dousset B, Benoist S, Vicaut E. Randomized clinical trial of early versus delayed temporary stoma closure after proctectomy. Br J Surg 2008;95(6):693-8.

8. Menegaux F, Jordi-Galais P, Turrin N, Chigot JP. Closure of small bowel stomas on postoperative day 10. Eur J Surg 2002;168(12):713-5.

9. Perez RO, Habr-Gama A, Seid VE, Proscurshim I, Sousa AH Jr, Kiss DR, et al. Loop ileostomy morbidity: timing of closure matters. Dis Colon Rectum 2006;49(10):1539-45.

10. Carlsen E, Bergan AB. Loop ileostomy: technical aspects and complications. Eur J Surg 1999;165(2):140-3.

11. Khair G, Alhamarneh O, Avery J, Cast J, Gunn J, Monson JR et al Routine use of gastrograffin enema prior to the reversal of a loop ileostomy. Dig Surg 2007;24(5):338-41.

12. Tang CL, Seow-Choen F. Digital rectal examination compares favourably with conventional water-soluble contrast enema in the assessment of anastomotic healing after low rectal excision: a cohort study. Int J Colorectal Dis 2005;20(3):262-6.

13. Kalady MF, Mantyh CR, Petrofski J, Ludwig KA. Routine contrast imaging of low pelvic anastomosis prior to closure of defunctioning ileostomy: is it necessary? J Gastrointest Surg 2008;12(7):1227-31.

14. Schechter S, Eisenstat TE, Oliver GC, Rubin RJ, Salvati EP. Computerized tomographic scan-guided drainage of intra-abdominal abscesses. Preoperative and postoperative modalities in colon and rectal surgery. Dis Colon Rectum 1994;37(10):984-8.

15. Cappell MS, Ghandi D, Huh C. A study of the safety and clinical efficacy of flexible sigmoidoscopy and colonoscopy after recent colonic surgery in 52 patients. Am J Gastroenterol 1995;90(7):1130-4.

16. Hasegawa H, Radley S, Morton DG, Keighley MR. Stapled versus sutured closure of loop ileostomy: a randomized controlled trial. Ann Surg. 2000 Feb;231(2):202-4.

17. Amin SN, Memon MA, Armitage NC, Scholefield JH. Defunctioning loop ileostomy and stapled side-to-side closure has low morbidity. Ann R Coll Surg Engl 2001;83(4):246-9.

18. Leung TT, MacLean AR, Buie WD, Dixon E. Comparison of stapled versus hand sewn loop ileostomy closure: a meta-analysis. J Gastrointest Surg 2008;12(5):939-44. Epub 2007 Dec 11.

19. Flikier-Zelkowicz B, Codina-Cazador A, Farrés-Coll R, Olivet-Pujol F, Martín-Grillo A, Pujadas-de Palol M. Morbidity and mortality associated with diverting ileostomy closures in rectal cancer surgery. Cir Esp 2008;84(1):16-9.

20. Saha AK, Tapping CR, Foley GT, Baker RP, Sagar PM, Burke DA, et al. Morbidity and mortality after closure of loop ileostomy. Colorectal Dis 2009;11(8):866-71. 